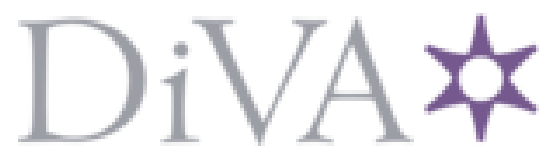

http://www.diva-portal.org

This is the published version of a paper published in Transportation Research Part D: Transport and Environment.

Citation for the original published paper (version of record):

Davari, M M., Jerrelind, J., Stensson Trigell, A. (2017)

Energy Efficiency Analyses of a Vehicle in Modal and Transient Driving Cycles including Longitudinal and Vertical Dynamics.

Transportation Research Part D: Transport and Environment, 53: 263-275

Access to the published version may require subscription.

N.B. When citing this work, cite the original published paper.

Permanent link to this version:

http://urn.kb.se/resolve?urn=urn:nbn:se:kth:diva-207786 


\title{
Energy efficiency analyses of a vehicle in modal and transient driving cycles including longitudinal and vertical dynamics
}

\author{
Mohammad Mehdi Davari*, Jenny Jerrelind, Annika Stensson Trigell
}

Department of Aeronautical and Vehicle Engineering, Division of Vehicle Dynamics and Centre for ECO² Vehicle Design, KTH Royal Institute of Technology, SE-100 44 Stockholm, Sweden

\section{A R T I C L E I N F O}

\section{Article history:}

\section{Keywords:}

Driving cycle

Rolling loss

Tyre

Wheel alignments

Environmental impact

Homologation

\begin{abstract}
A B S T R A C T
The growing concerns about the environmental issues caused by vehicles and a strive for better fuel economy, urge the legislators to introduce conservative regulations on vehicle testing and homologation procedures. To have accurate evaluations, driving cycles that can sufficiently describe the vehicles' conditions experienced during driving is a prerequisite. In current driving cycles there are still some issues which are disregarded. The aim of the presented work is to study the contribution of chassis and vehicle dynamics settings on tyre rolling loss in comparison with the original assumptions made in the NEDC, FTP and HWFET driving cycles. A half-car model including a semi-physical explicit tyre model to simulate the rolling loss is proposed. For the chosen vehicle and tyre characteristics, depending on the specific chassis settings and considered driving cycle, considerable difference up to $7 \%$ was observed between the energy consumption of the proposed- and conventional approach. The current work aims to provide the legislators with a better insight into the real effects of chassis and vehicle dynamics during the certification process to further improve the test related procedures required for homologation such as generation of road load curves. I.e., the aim is not to provide a new homologation process, since there are also other effects such as road roughness and tyre temperature that need to be considered. The results are also of interest for the vehicle manufacturers for further considerations during test preparation as well as in the development phase in order to reduce the environmental impacts.
\end{abstract}

(c) 2017 Elsevier Ltd. All rights reserved.

\section{Introduction}

Nowadays, when launching new vehicles, most countries have type approval emission tests that the vehicles need to pass. Considering that the vehicle emissions are rather variable and therefore have different environmental impacts, it is important to perform the tests under standardised laboratory conditions to ensure a reproducible and reliable test procedure. A driving cycle is therefore commonly used as a standard test defined by legislators, which allows the accomplishment of emission tests in a reproducible manner. This includes a record of the vehicle speed and gear selection in the time domain.

Different perspectives of regulatory organisations lead to introduction of various driving cycles which could either be used generally (Dembski et al., 2002) or regionally in specific city or country (André et al., 1995; Hung et al., 2007; Wang et al., 2008; Kamble et al., 2009) in order to measure the emission performance of vehicles. Simultaneously, many efforts

\footnotetext{
* Corresponding author.

E-mail address: mmdavari@kth.se (M.M. Davari).
} 
and research have been made to either reveal the existing discrepancies in the current homologation process (Pelkmans and Debal, 2006; Kühlwein, 2016) or optimise the driving cycles in order to improve the test procedures towards a more realworld emission performance (Amirjamshidi and Roorda, 2015; Rapone et al., 1995; Bata et al., 1994; Kishan et al., 1993; UNECE). Even though the results of these efforts have improved the test procedures, there are still some simplifications in the conventional test procedures and modifications by vehicle manufacturers during tests that might be of importance for the estimation of fuel consumption in type approval process (Kühlwein, 2016).

Most driving cycles used for homologation are normally performed using a stationary vehicle tied down on a chassis dynamometer where the load on the wheels are adjusted to simulate driving resistances on the vehicle, such as rolling resistance and aerodynamic drag (Dembski et al., 2002; Kühlwein, 2016). These characteristics are conventionally considered as coefficients, which are often considered to be constant during the whole test. However, based on the type of vehicle, its powertrain, weight and dimensions as well as other chassis components like suspension and tyres, those coefficients can be subjected to changes, thus influencing the fuel consumption and emission performance of the vehicle in real-world driving.

Among all resistive forces in a passenger car, the rolling resistance is one of the characteristics that is highly dependent on the load change, speed and wheel alignment settings. Rubber deformation results in rolling loss and some of the different ways that deformations in the tyre can occur, and thereby contribute to the tyre energy dissipation, are illustrated in Fig. 1 (Davari et al., 2015; Davari, 2015). The current certification process under estimate the vehicle emissions due to their inadequate representation of chassis components and vehicle dynamics compared with the performance of a vehicle in realworld driving wherein for instance the chassis or suspension are sometimes adjusted/adapted by the manufacturers (Kühlwein, 2016).

Without understanding the mechanism of rolling loss and realise its contribution to the driving resistances and accuracy of certification process, suggestions on the improvement of current certification procedures cannot be made realistically. In this work, consequences of the assumption of no wheel alignments and no load transfer, made in current procedures, are investigated with the focus on rolling loss estimation. I.e., the contributions to rolling loss from chassis and suspension kinematics by considering longitudinal and vertical dynamics of the vehicle are estimated and compared. Here, the main European and US driving cycles are used as case studies to evaluate the vehicle energy consumption. Essentially, this paper is aimed to specifically investigate the contribution of chassis and related vehicle dynamics issues on the result of homologation process which are missed until now. Therefore, this work will not suggest a new driving cycle, rather provides a broader insight into the contribution of the chassis and vehicle dynamics on the certification results, which are somehow eliminated todays, thereby suggesting further consideration of those parameters during homologation by either modifying the test procedures or test benches.

\section{Background}

\subsection{Driving cycles}

A driving cycle is a standardised driving pattern, which is used to gain a quantitative understanding of fuel consumption and emissions for a vehicle during either development phase or homologation process, or they might also be used for engine

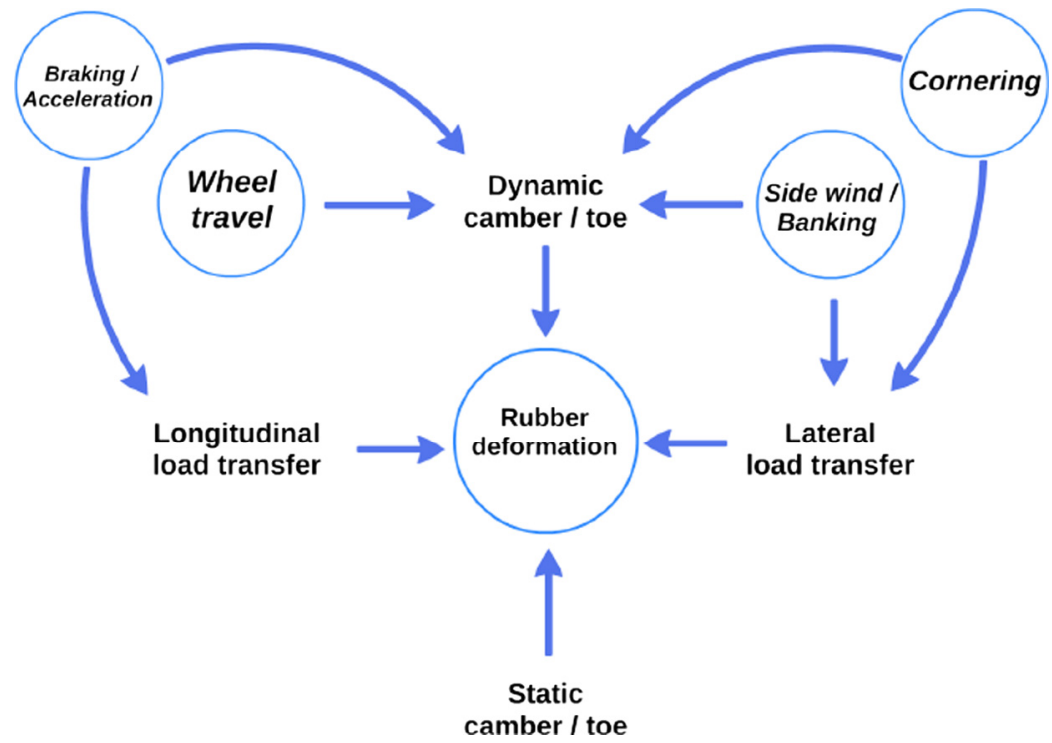

Fig. 1. The deformation mechanisms induced on a tyre (Davari, 2015). 
and drivetrain durability tests. These patterns are generally composed of specific speed trajectories over time where the effect of road inclination and road roughness can also be considered. Generally, the driving cycles are categorised in two clusters namely; modal cycles such as the European standard NEDC (New European Driving Cycle) and transient cycles such as HWFET (Highway Fuel Economy Test) and FTP (Federal Test Procedure), which are used in the United States (Barlow et al., 2009). The modal cycles are composed of constant speed periods and acceleration and deceleration phases while transient cycles are comprised of wider range and variation of speeds and accelerations.

In Europe and some other countries the NEDC is used as reference cycle for homologation process, see Fig. 2(a). This cycle is composed of two main sections where the first part resembles the urban driving with four similar consecutive sections reaching a maximum speed of $50 \mathrm{~km} / \mathrm{h}$ while the last section shows the extra urban driving scenario with the maximum speed of $120 \mathrm{~km} / \mathrm{h}$. There are also other driving cycles such as Artemis driving cycles (Andre, 2004), which are not commonly (or intended to be) used for certification of emission or fuel economy. Such kinds of cycles are used in the vehicle industry for better understanding of the vehicle performance in more real-world driving conditions during the development phase and before the homologation process. The FTP cycle has been created by US Environmental Protection Agency (EPA) to represent urban driving including frequent start-stops, see Fig. 2(b), while the HWFET is used for assessment procedures of highway driving, see Fig. 2(c). These cycles serve as the regulatory assessment benchmark tests for vehicle certification in US (Dembski et al., 2002).

In this work the NEDC, HWFET and FTP are chosen for the case studies. Characteristics of these driving cycles are shown in Table 1.

\subsection{Rolling resistance}

Among all the resistances working against the vehicle movement, rolling resistance is one of the influential loss parameters which the engine has to overcome. Generally, the rolling resistance coefficient used to estimate the vehicles fuel economy, is based on the standard ISO 28580 that is determined at one operating point of the tyre. In either the test benches or the software tools provided to estimate the fuel economy of vehicles in different driving cycles, different approaches are used to consider the rolling resistance. Some of those consider the rolling resistance contribution as a constant coefficient based on ISO 28580 (Dembski et al., 2002) or as a trigonometric function or as a mathematical model, either linear (Kiencke and Nielsen, 2003) or nonlinear (Wong, 2001; Sandberg, 2001), that characterises the rolling resistance behaviour as an affine function of the vehicle speed and independent variables. In different studies (Ali et al., 2013; Krantz et al., 2013; Davari et al., 2017) and measurements (Peckelsen and Gauterin, 2013; Bode \& Bode, 2013) it is shown that the chassis settings and the wheel alignments have a contribution to the rolling resistance. Therefore, in this paper a more advanced tyre model that is able to consider the influence of chassis settings on rolling loss is used to perform a more comprehensive study.

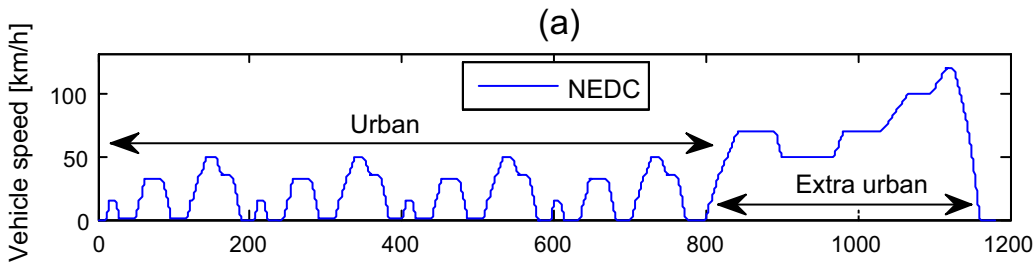

(b)

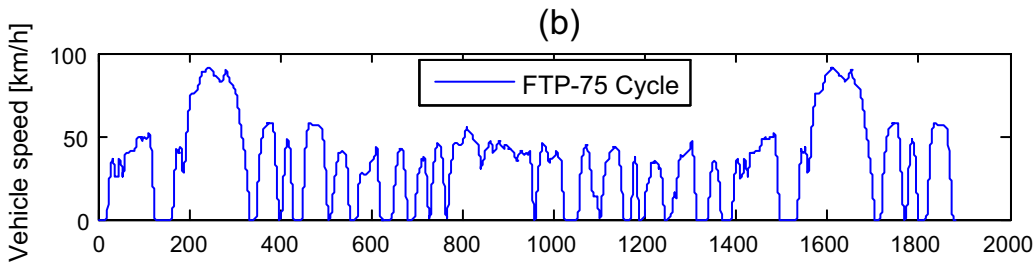

(c)

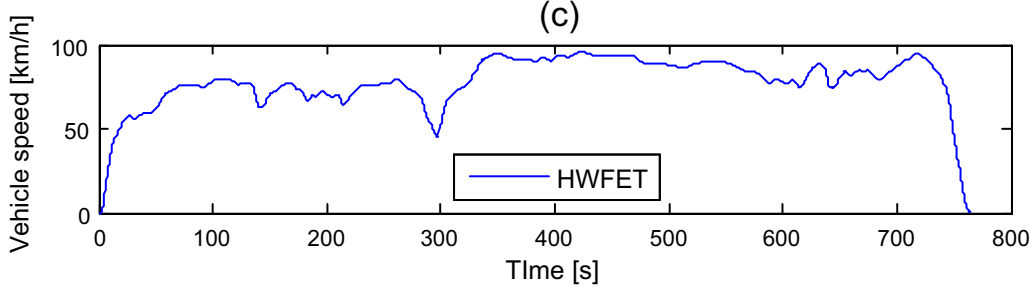

Fig. 2. Driving cycles. (a) NEDC, (b) FTP-75, and (c) HWFET (Barlow et al., 2009). 
Table 1

Characteristics of chosen driving cycles.

\begin{tabular}{llll}
\hline Driving cycle & NEDC & FTP & HWFET \\
\hline Distance $[\mathrm{m}]$ & 11,017 & 17,787 & 16,503 \\
Duration [s] & 1180 & 1874 & 765 \\
Average speed [km/h] & 33.6 & 34.2 & 77.7 \\
\hline
\end{tabular}

\subsection{Motivation}

In order to explore the extent of camber and toe changes during the vehicle movement under dynamic loads, a vehicle model with six DOF, including translational and rotational motions in longitudinal, lateral and vertical axes, was evaluated using ADAMS car software (MSC Software) with the vehicle parameters listed in Table 2. The results provided from the Multi Body Simulation in ADAMS are here used as the motivation of this study. The aim of these results is to show how the wheel alignments can change during the driving cycles and to show their significance. Fig. 3 shows the simulation results of the dynamic changes of toe and camber during an exemplary driving cycle that is extracted from the NEDC by considering the Extra Urban driving cycle and the first part of the Urban driving cycle. The front suspension used in the model is McPherson and the rear suspension utilises the Double Wishbone system.

In this study no static wheel alignment has been assigned to the suspension. However, it can be seen that dynamic changes can be even higher than the static alignments that might be assigned to the vehicle suspension, for instance see the plot of toe angle in Fig. 3(c). The current changes in the values are originating from the suspension kinematics and could be different for different type of suspension and chassis structure.

\section{Modelling}

To perform the investigations a tyre model that can simulate rolling losses is needed, as well as a vehicle model that takes into account the vertical- and pitch motions. Even though the ADAMS model previously used is a high fidelity model suitable for kinematic and dynamic analyses, it will result in high computational effort if upgraded with a more advanced tyre model capable of simulating the rolling loss. Therefore a less complicated vehicle model, a 2-DOF half-car model, is used in combination with a tyre model named EBM. Both models are further described below.

\subsection{Vehicle model}

A 2 DOF half-car model is used to describe the motions that represent the vertical and pitch dynamics of the vehicle body and vertical motions of front and rear suspensions, see Fig. 4. The road surface is assumed to be flat in this work. The vehicle data represent a midsize SUV with the parameters listed in Table 3.

The equations of motion are formulated so that pitch angle, $\theta$, and vertical motion in centre of gravity, $z$, are zero at the unloaded position of the system. Also the pitch angle, $\theta$, is assumed to be small, thereby small angle approximation is used;

$$
\begin{aligned}
& m \ddot{z}=F_{f}+F_{r}-m g \\
& I_{y y} \ddot{\theta}=-F_{f} \cdot l_{f}+F_{r} \cdot l_{r}+M_{P} \\
& F_{f}=2 \cdot k_{f}\left(z-l_{f} \theta\right)+2 \cdot c_{f}\left(\dot{z}-l_{f} \dot{\theta}\right)
\end{aligned}
$$

Table 2

Full vehicle model data.

\begin{tabular}{ll}
\hline Parameter & Value \\
\hline CG distance to front axle $\left(l_{f}\right)$ & $1.301 \mathrm{~m}$ \\
CG distance to rear axle $\left(l_{r}\right)$ & $1.473 \mathrm{~m}$ \\
Vehicle mass $(m)$ & $1936 \mathrm{~kg}$ \\
CG distance from ground $(h)$ & $0.506 \mathrm{~m}$ \\
Body moment of inertia around y axis $\left(I_{x x}\right)$ & $1500 \mathrm{~kg} \mathrm{~m}$ \\
Body moment of inertia around y axis $\left(I_{y y}\right)$ & $3477 \mathrm{~kg} \mathrm{~m}^{2}$ \\
Body moment of inertia around y axis $\left(I_{z z}\right)$ & $4400 \mathrm{~kg} \mathrm{~m}{ }^{2}$ \\
Front suspension stiffness $\left(k_{f}\right)$ & $16,500 \mathrm{~N} / \mathrm{m}$ \\
Rear suspension stiffness $\left(k_{r}\right)$ & $28,000 \mathrm{~N} / \mathrm{m}$ \\
Front suspension damping $\left(c_{f}\right)$ & $4500 \mathrm{Ns} / \mathrm{m}$ \\
Rear suspension damping $\left(c_{r}\right)$ & $3500 \mathrm{Ns} / \mathrm{m}$ \\
Static toe $(\alpha)$ & $0^{\circ}$ \\
Static camber $(\gamma)$ & $0^{\circ}$ \\
\hline
\end{tabular}


(a)

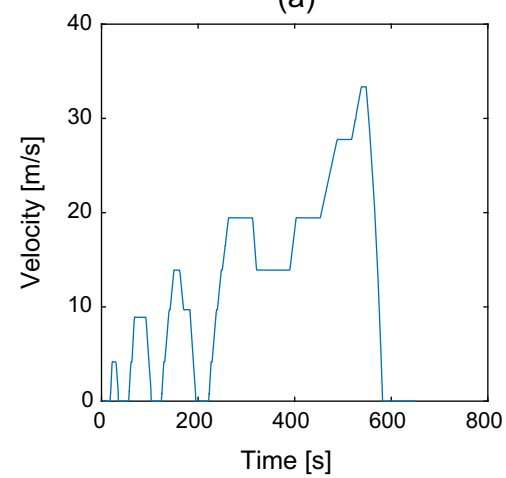

(b)

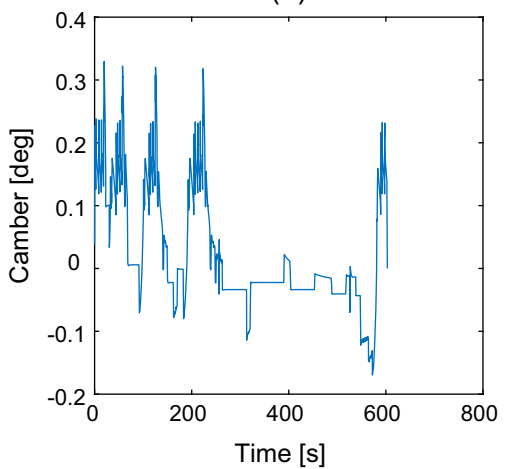

(c)

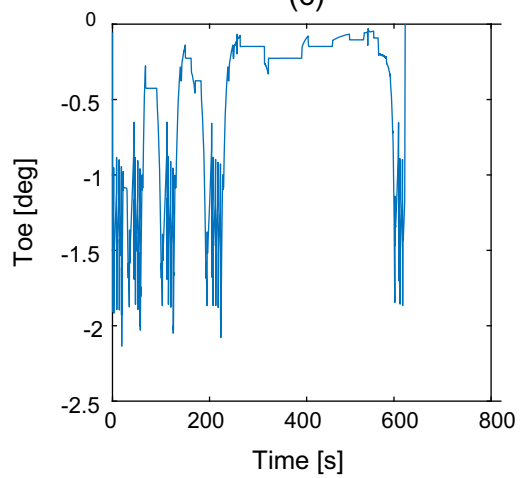

Fig. 3. Dynamic change of wheel alignments of the vehicle model during an exemplary driving cycle, (a) velocity profile, (b) camber angle, and (c) toe angle.

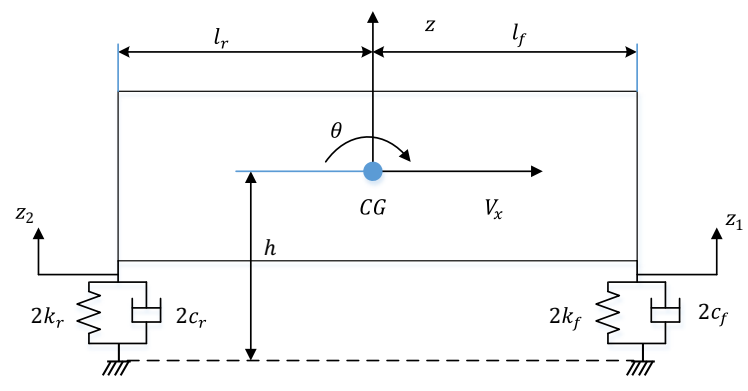

Fig. 4. Half-car model with its parameters.

$$
F_{r}=2 \cdot k_{r}\left(z+l_{r} \theta\right)+2 \cdot c_{r}\left(\dot{z}+l_{r} \dot{\theta}\right)
$$

where $\ddot{\theta}$ is the pitch acceleration of the vehicle body and $M_{P}$ is the torque generated at acceleration/deceleration; with the pitch centre located at the CG, thus calculated as

$$
M_{P}=m \cdot \ddot{x} \cdot h
$$

with $\ddot{x}$ as the longitudinal acceleration/deceleration.

\subsection{Tyre model}

The rolling loss of a tyre is mainly specified by internal losses and external losses (Davari, 2015). The first one is referring to the dissipation inside the rubber due to the viscoelastic nature of the tyre structure. The second one is referring to the loss of energy caused by the sliding of the bristles in the contact patch which can occur in different regions of the contact patch, for example during cornering, acceleration, and braking. There are also other parameters that influence the overall rolling loss directly or in-directly. These parameters can be categorised in four levels namely: vehicle, chassis, tyre, and road where each level corresponds to different parameters depicted in Table 4.

Table 3

Half-car model data.

\begin{tabular}{ll}
\hline Parameter & Value \\
\hline CG distance to front axle $\left(l_{f}\right)$ & $1.301 \mathrm{~m}$ \\
CG distance to rear axle $\left(l_{r}\right)$ & $1.473 \mathrm{~m}$ \\
Vehicle mass $(m)$ & $1936 \mathrm{~kg}$ \\
CG distance from ground $(h)$ & $0.506 \mathrm{~m}$ \\
Body moment of inertia around y axis $\left(I_{y y}\right)$ & $3477 \mathrm{~kg} \mathrm{~m}{ }^{2}$ \\
Front suspension stiffness $\left(2 k_{f}\right)$ & $33,000 \mathrm{~N} / \mathrm{m}$ \\
Rear suspension stiffness $\left(2 k_{r}\right)$ & $56,000 \mathrm{~N} / \mathrm{m}$ \\
Front suspension damping $\left(2 c_{f}\right)$ & $9000 \mathrm{Ns} / \mathrm{m}$ \\
Rear suspension damping $\left(2 c_{r}\right)$ & $7000 \mathrm{Ns} / \mathrm{m}$ \\
\hline
\end{tabular}


Table 4

Categorisation of external influential parameters on rolling loss (Davari, 2015).

\begin{tabular}{lll}
\hline Vehicle level & Chassis level & Tyre level \\
\hline $\begin{array}{l}\text { Longitudinal speed } \\
\text { Vertical force } \\
\text { Slip ratio }\end{array}$ & $\begin{array}{l}\text { Side slip angle } \\
\text { Camber angle }\end{array}$ & Pressure (vertical stiffness) \\
& & \\
\hline
\end{tabular}

The tyre model used in this study is a semi-physical explicit tyre model called EBM (Extended Brush tyre Model) earlier developed by the authors (Davari et al., 2017). The EBM is based on the brush tyre theory (Hadekel, 1952) and is capable of simulating the rolling loss in the tyre within vehicle simulations. Compared with other available tyre models, the EBM uses relatively few physical parameters but is still capable of capturing the tyre behaviour in a good manner. The model is dependent on the vertical dynamics, speed and wheel alignments, i.e. camber and toe angles, in order to describe the states of the tyre in motion. The implemented tyre data in this study are shown in Table 5. The simulations were performed with the assumption of a free rolling tyre during the whole cycle. Therefore, the results will be isolated from the effect of longitudinal slip on the rolling loss. In addition, the tyres are assumed to be in their operating condition thus having a constant tyre pressure. The road is assumed to be flat; therefore, no road roughness is included in this work.

The tyre model is able to simulate the rolling loss including the rolling resistance coefficient and other losses in the contact patch and tyre structure. The rolling loss is a dynamic parameter that can be influenced by the driving conditions and vehicle states. For instance the rolling resistance depends on different parameters such as speed, load and suspension kinematics, and as explained in Section 1, the load transfer causes the tyre load and suspension kinematics to change thus influencing the rolling resistance. Fig. 5 shows these relations extracted from EBM for the chosen tyre in the study. Furthermore, Fig. 6 illustrates the change in energy dissipation for the chosen tyre under different wheel alignments and constant load.

\subsection{Coupled tyre-vehicle model}

Using the tyre model, the influence of vehicle dynamics and kinematics on rolling loss can be considered in the previously introduced driving cycles. In order to perform full vehicle simulations, the tyre and the vehicle models are coupled together. As input, the driving cycle is prescribed to the coupled model where the longitudinal and vertical dynamics of the model such as pitch and bounce motions are gained at the vehicle model part, see Fig. 7. The load transfer and the pitch behaviour in the vehicle model will be the inputs into the tyre model in form of wheel loads. Finally, under specific tyre conditions over the whole cycle, rolling loss will be calculated.

Considering that in this study the wheels will only be set to different camber and toe angles, it is acceptable to solely consider the longitudinal and vertical motions of the vehicle and tyre, since in real case, the full vehicle is symmetrical and lateral effects of suspension in a symmetrical setting will be balanced. This assumption is also valid here since the road is assumed to be flat without any irregularities or banking.

\section{Results and discussion}

For simulation of driving cycle effects, the NEDC, FTP and HWFET are chosen as described in Section 2. The loading conditions and the wheel speed will vary during acceleration and deceleration phases. Fig. 8 shows the body dynamics as well the axles' loads for the chosen vehicle during each driving cycle. In order to obtain the reference state, an initial simulation is performed and used for comparison between the different cases. The wheel alignments in the reference vehicle are set to zero toe $(\alpha)$ and zero camber $(\gamma)$ angles. Then, studies of different combinations of wheel alignments are performed. The range of these alignments are within the range of wheel settings which are commonly used by different car manufacturers where the toe angle will not exceed $0.5^{\circ}$ and the camber angle will be around $1-2^{\circ}$. As can be seen in Fig. 8 , the maximum acceleration and deceleration for all driving cycles doesn't exceed $1.5 \mathrm{~m} / \mathrm{s}^{2}$. However, the body dynamics increases from NEDC to FTP driving cycle.

When implementing the advanced tyre model coupled with the vehicle model and performing the analyses, interesting results are found regarding the rolling resistance. Considering the dynamics of the vehicle body i.e. the load transfer, the wheel conditions will change during the driving cycle, which result in changes in the rolling resistance, $F_{r}$, see Figs. $9-11$. As depicted in respective plots, the rolling resistance of front and rear axles during the whole cycle in the conventional method (red plots) is only a function of speed; while, the effect of body dynamics and the load transfer cause additional change of load on axles thereby a load and speed dependent rolling resistance is recorded during the cycle using the proposed approach (blue plots).

Table 5

\begin{tabular}{ll} 
The implemented tyre data. & \\
\hline Size & $235 / 75 \mathrm{R} 15$ \\
Vertical/Lateral stiffness & $1117 / 1900 \mathrm{kN} / \mathrm{m}$ \\
Vertical/Lateral damping & $38 / 133 \mathrm{Ns} / \mathrm{m}$
\end{tabular}


(a)

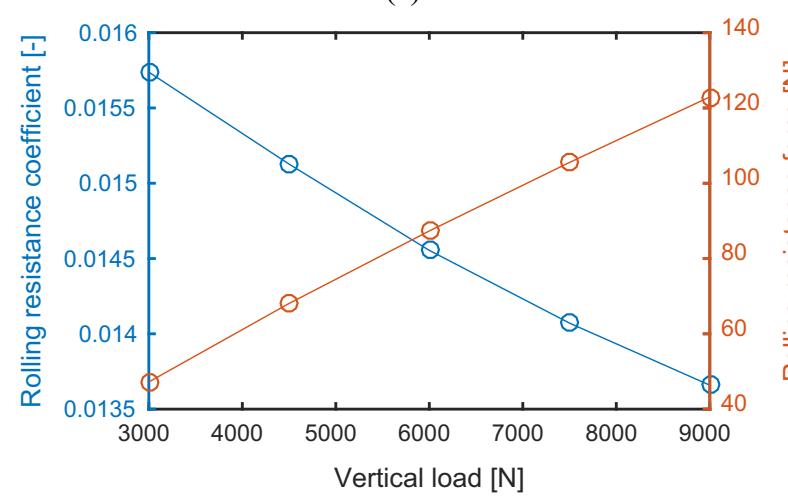

(b)

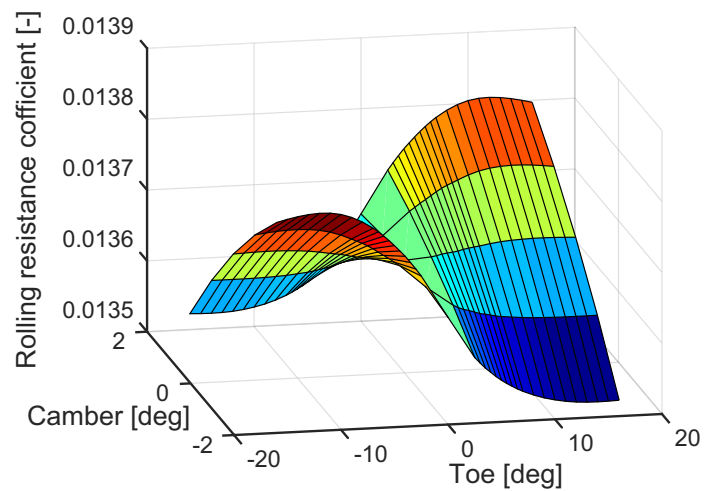

Fig. 5. (a) Dependency of rolling resistance coefficient on vertical load, (b) rolling resistance coefficient as function of wheel alignment for the studied tyre.

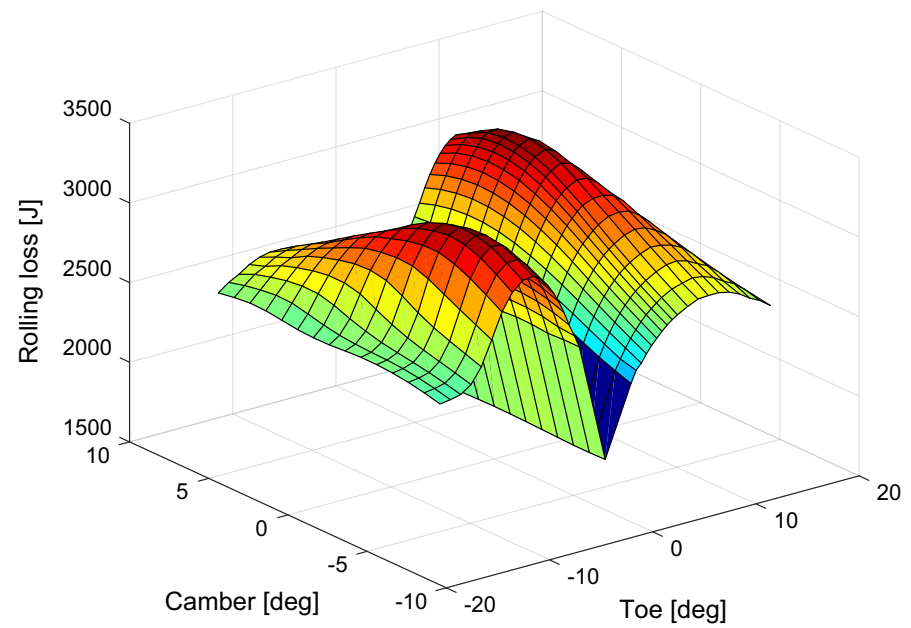

Fig. 6. Energy dissipation in the tyre/road interaction as function of wheel alignment for the studied tyre.

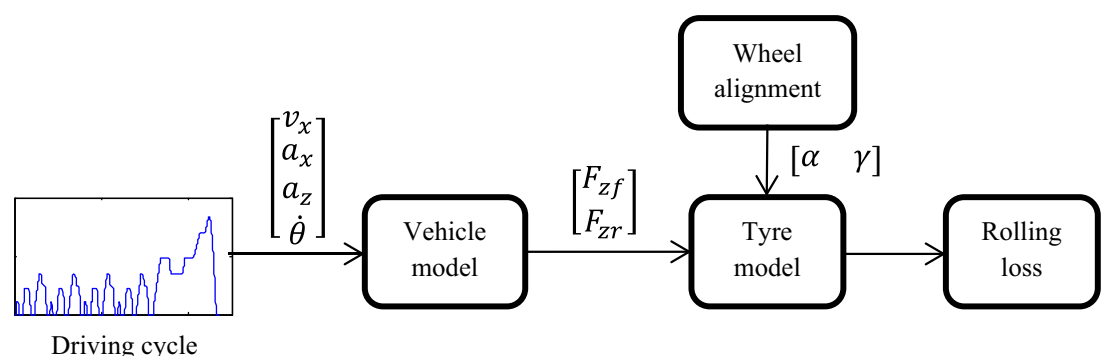

Fig. 7. Flow diagram of rolling loss calculation in the coupled tyre-vehicle model.

From this case study, the front axle is shown to have higher contribution to the rolling resistance than the rear axle during the NEDC cycle which can be explained by the position of the centre of gravity in the chassis which affect the amount of static forces as well the transferred forces during the acceleration and deceleration. However, this behaviour and the difference between the rolling resistance of front and rear axles are not unique and are subjected to changes. This can also be influenced by the type of tyres used in front and rear.

Among all, the important point to be considered here is the load sensitivity effect of the tyres as their natural characteristic; which are also considered in the tyre model. This characteristic causes the tyre to demonstrate a non-linear behaviour under load change. While the load transfer of the axles follows a linear relation, their contribution on the rolling resistance 
(a)
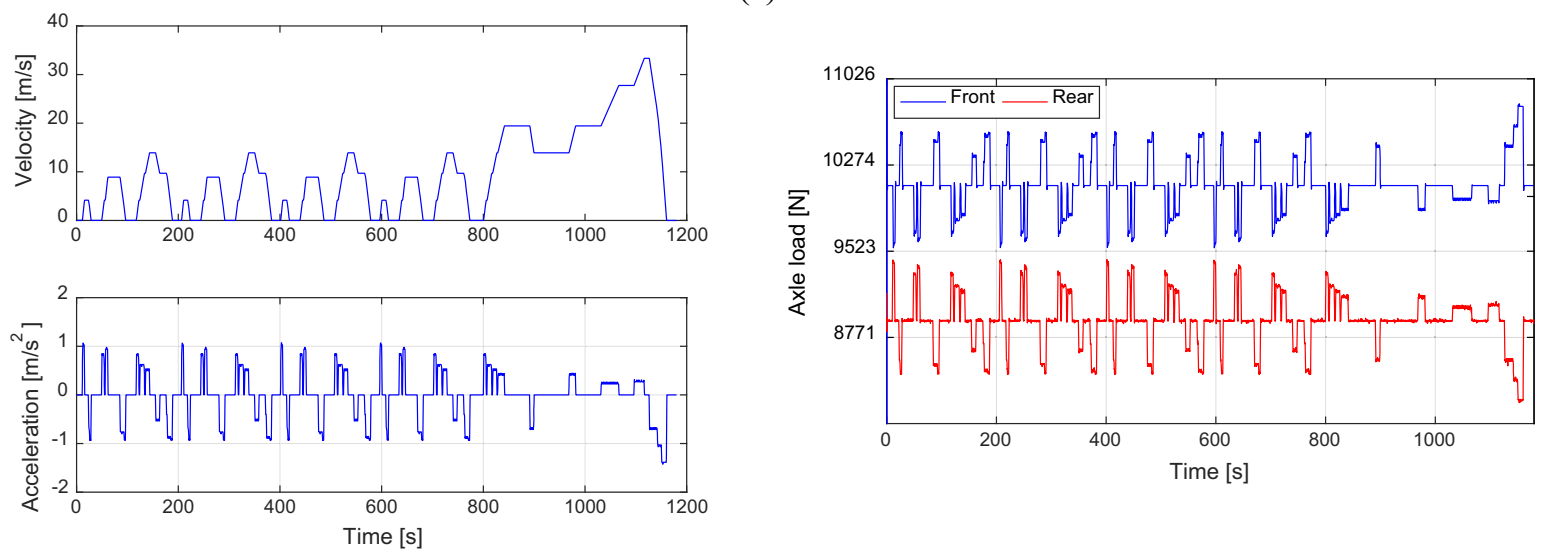

(b)
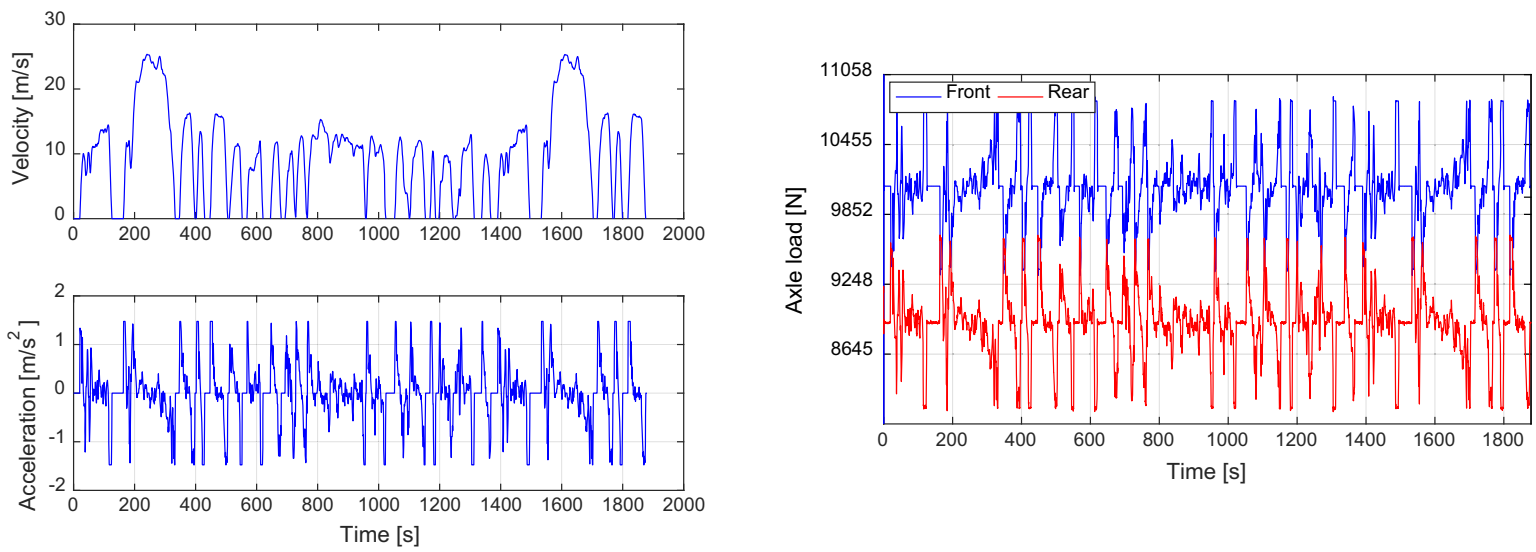

(c)
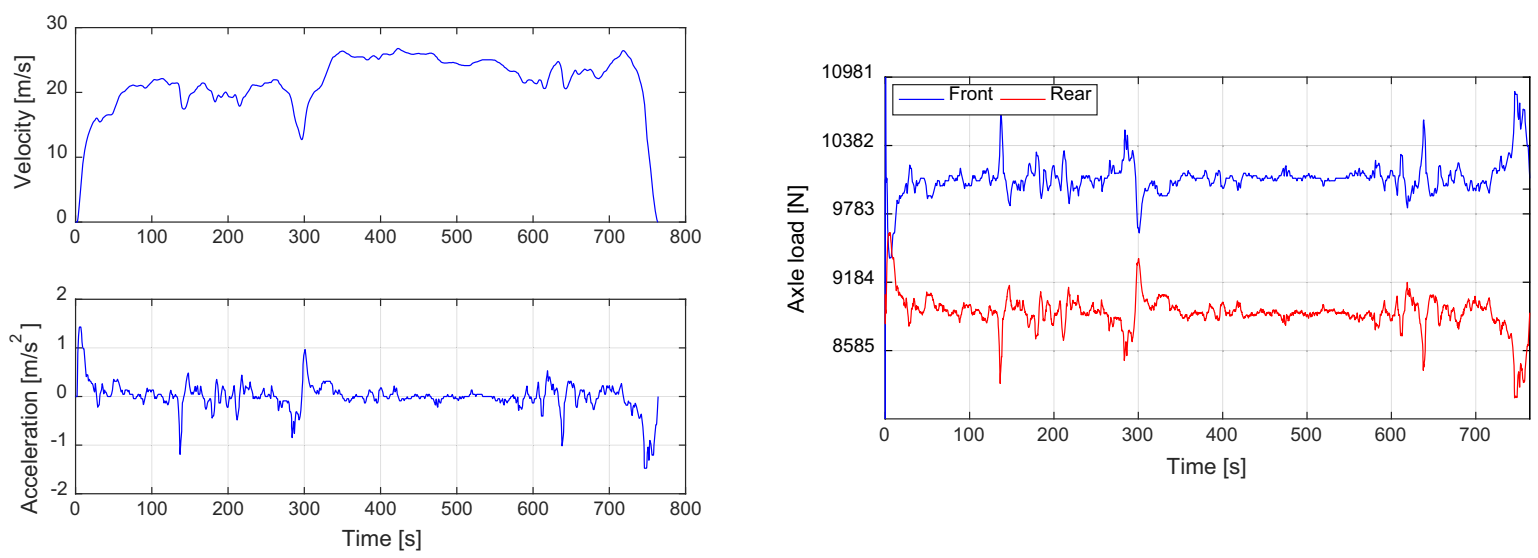

Fig. 8. Simulated body dynamics and the axles' forces for each driving cycle. (a) NEDC, (b) FTP and (c) HWFET.

coefficient and thereby the rolling resistance force, is not linear anymore. This phenomenon can be observed in Fig. 12. As can be seen for the considered tyre, depending on the arrangement of wheel alignment, a maximum difference of about $12 \%$ in rolling resistance due to load sensitivity effect is found.

In addition to that, the type of suspension affects the chassis behaviour during pitch and bounce. Therefore, the rolling resistance of axles during driving cycle can show either higher or lower values in other cases. These phenomena will result in a difference between the estimated power losses within different driving cycles. Fig. 13 shows the differences between the power losses of conventional and proposed approach by only considering the effect of pitch and bounce dynamics (without taking into account the toe and camber). As depicted, the difference in the FTP is smaller which is also comprehensible 
a)

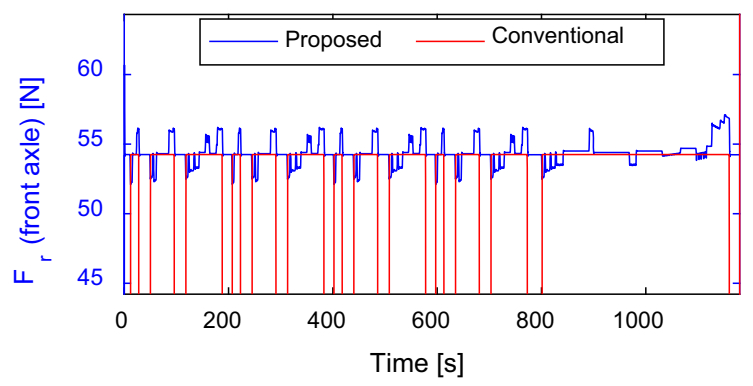

b)

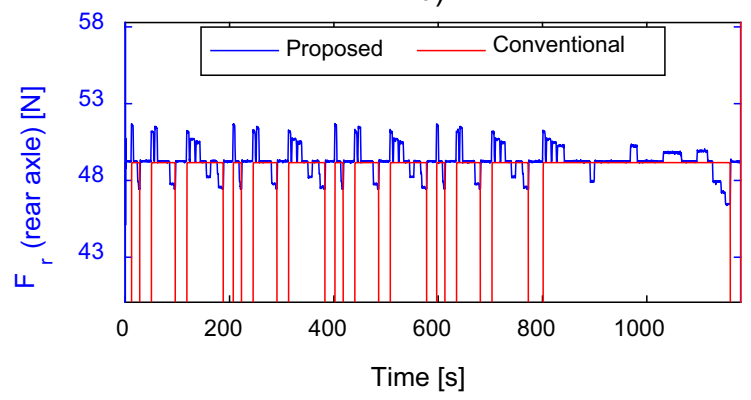

c)

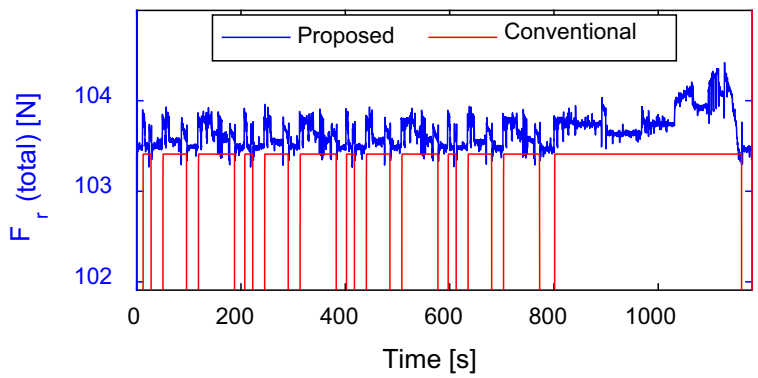

d)

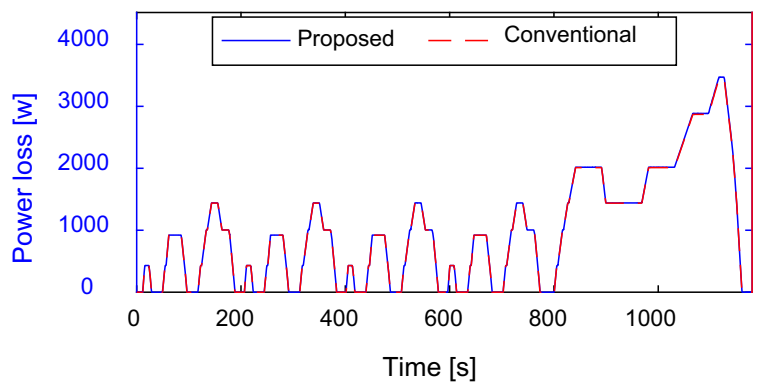

Fig. 9. Analysing the rolling resistance behaviour in proposed and conventional approach for NEDC.

a)

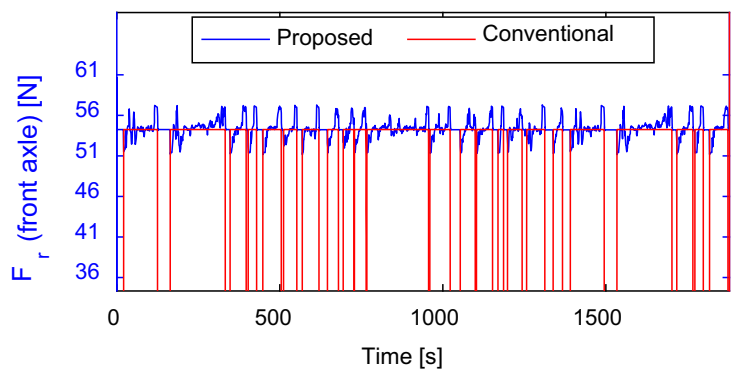

b)

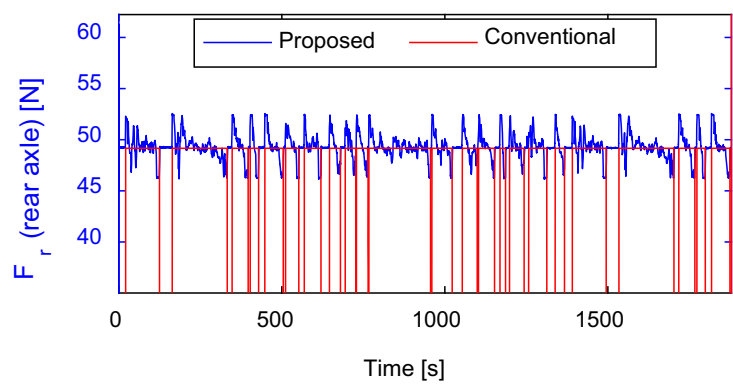

c)

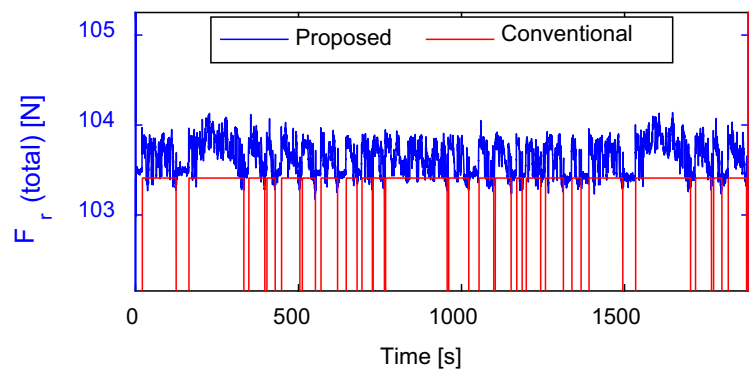

d)

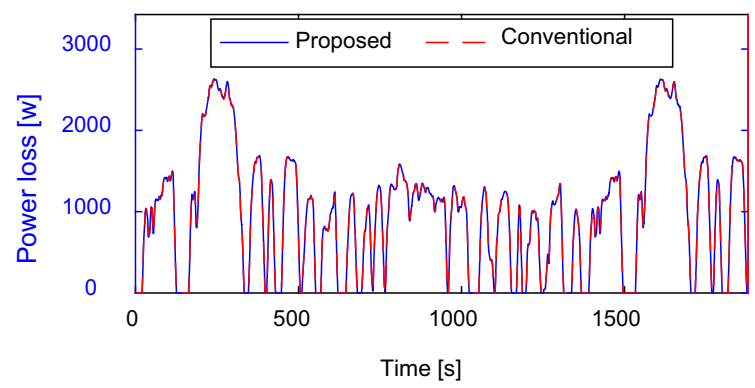

Fig. 10. Analysing the rolling resistance behaviour in proposed and conventional approach for FTP driving cycle.

when its chassis dynamics is compared with the dynamics generated in NEDC and HWFET driving cycles. Though these results are not unique and could be different for different vehicle and tyre combinations, it is obvious how the total rolling resistance can vary over a driving scenario. In addition to the static values assigned to suspension settings, these alignments will be subjected to variations during acceleration and deceleration according to the type of suspension and vehicle characteristics. 
a)

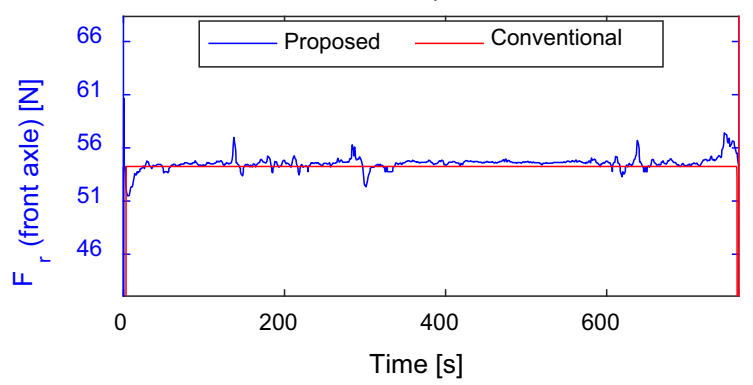

b)

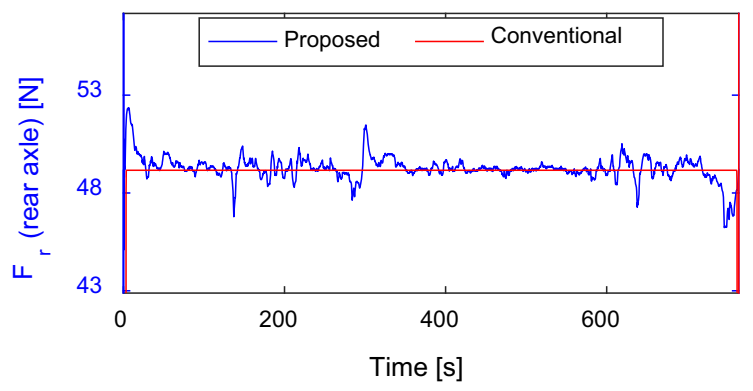

c)

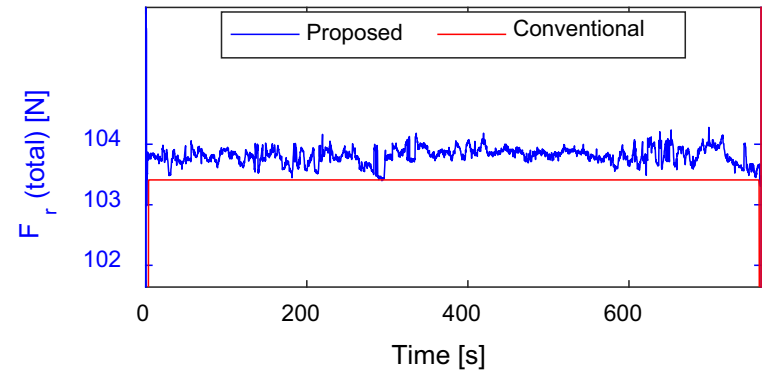

d)

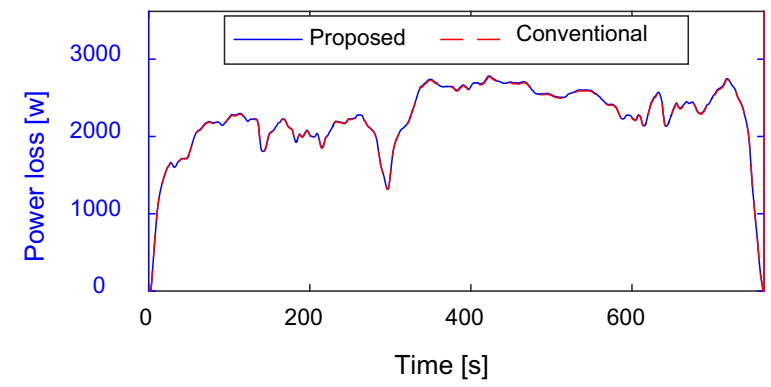

Fig. 11. Analysing the rolling resistance behaviour in proposed and conventional approach for HWFET driving cycle.

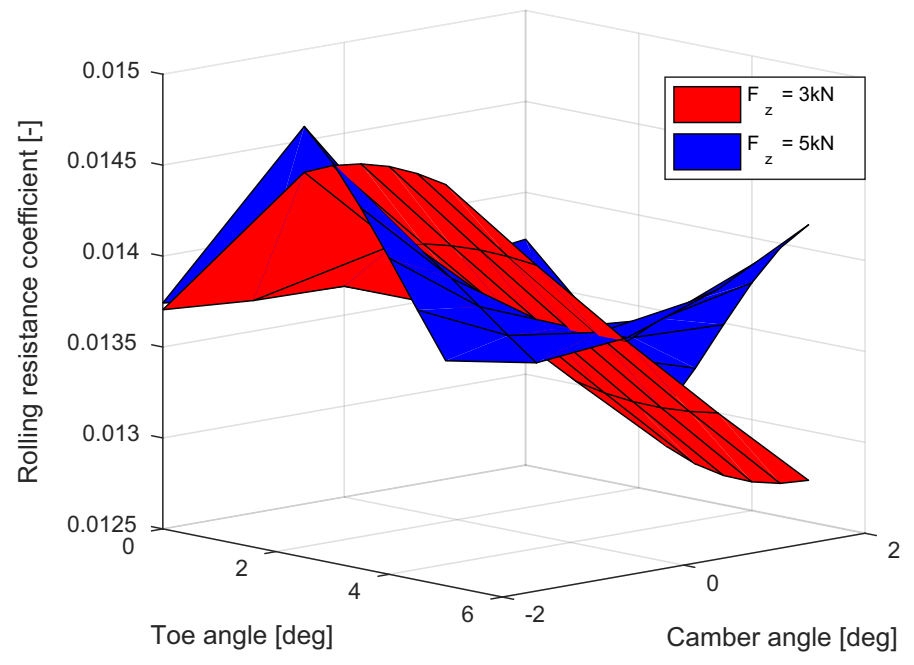

Fig. 12. Load sensitivity effect.

Further analyses of the energy loss with the half-car model show a considerable difference between the results where no wheel alignment was applied and the situations where the wheel was set to different values, i.e. different toe and camber angles. This will represent more realistic driving scenarios, since to gain optimum handling and dynamics for a vehicle, depending on the suspension and vehicle characteristics, static wheel alignments will be set to the suspension by car manufacturers. This exposes additional deflection and resisting forces to the tyre causing more losses, as explained in Section 3.2. Fig. 14 shows a comparison of the effect of different combination of wheel alignments on the rolling loss during the NEDC driving cycle obtained with the simulations of the half-car model coupled with the EBM.

As depicted in Fig. 14, the most influential parameter on the rolling loss comes from the toe resistance, however, a combination of the camber and toe can have different outcomes in different part of the cycle. As shown, the camber might not influence the total energy loss of urban driving considerably, but combination of a negative camber with a positive toe angle can reduce the energy loss. This can be explained by the correcting effect of camber on the pressure distribution of the 


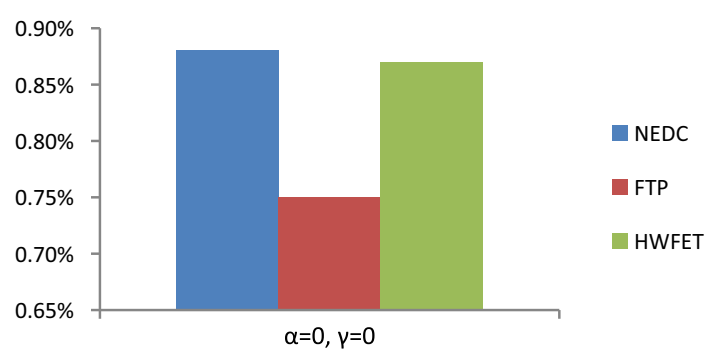

Fig. 13. Difference between the power losses obtained from the proposed and conventional approach for the reference case, i.e., no wheel alignments, for the three studied driving cycles.

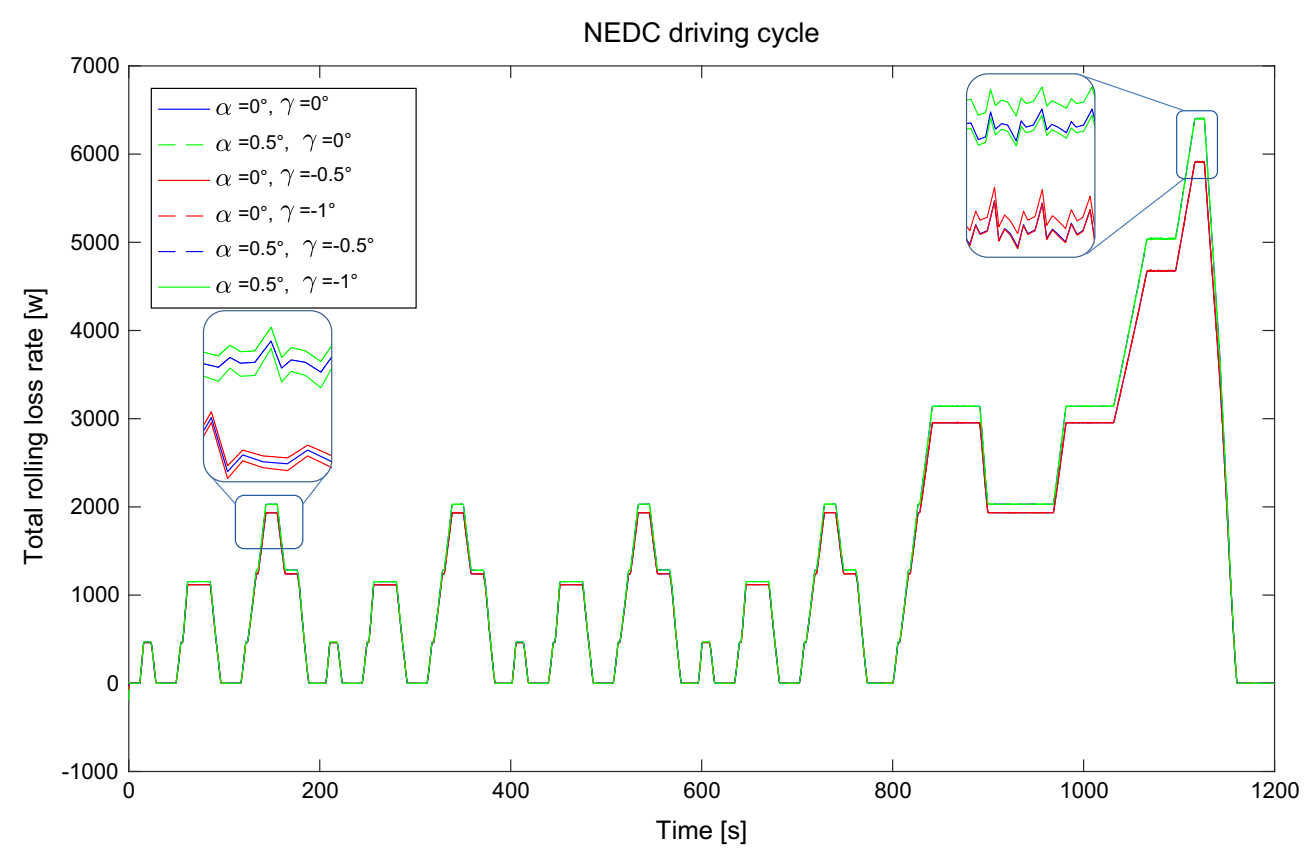

Fig. 14. Analysing total rolling loss rate of different wheel alignment settings during NEDC using half-car model.

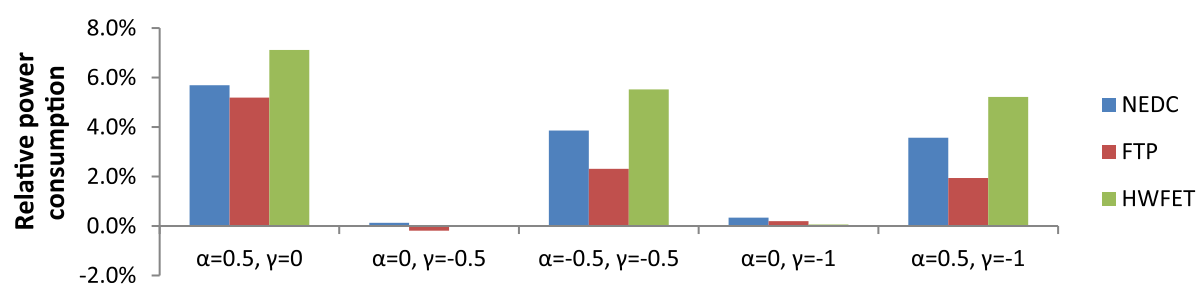

Fig. 15. Relative power consumption for different wheel alignments in different driving cycles.

contact patch and deflection of the carcass, which reduces the total deflection and thereby the energy loss in the tyre (Davari et al., 2017). The results of different driving cycles for different combinations of toe and camber using the combined vehicle and tyre model are summarised in Fig. 15. The values show relative changes to the reference case, i.e., a vehicle without any wheel alignments. $(\alpha=0, \gamma=0)$. For example, the FTP driving cycle which imposes high dynamics on the chassis show the lowest relative consumption among all the cycles and even slightly overestimates the losses for the wheel alignment combination $(\alpha=0, \gamma=0.5)$. This means that with small camber changes up to $-0.5^{\circ}$ while having no toe change, the FTP driving cycle can still provide reasonable results. However, as can be seen in other cases, by increasing the wheel alignments, the driving cycles show more deviation from the reference due to increase in the rolling loss as previously shown and discussed. On the other hand, the effect of wheel alignment' change can cause deviations from the results of the existing driving cycles discussed in this paper which can be accounted as a source of uncertainty in the performance of such driving cycles. 


\section{Conclusions}

In this paper a model including the Extended Brush tyre Model (EBM) which adds the ability to simulate the rolling loss during different vehicle manoeuvres, together with a half-car vehicle model that considers the pitch and bounce motion (i.e. load transfer between front and rear axle), have been proposed as a base for studies of energy consumption during different driving cycles. The simulations were performed with different wheel alignments, i.e. different camber and toe angles. The results were compared with a reference case were no wheel alignments were applied. The outcomes show considerable difference in the rolling loss within different parts of the cycle, in which for the chosen SUV and tyre, up to 7\% difference in relative power consumption was observed depending on the specific chassis settings and considered driving cycle, see Fig. 15. I.e. the conventional procedure is underestimating some existing losses while doing the certifications. The notable result is that, the more dynamic the driving cycle is, the less difference exists between the two methods. Furthermore, it can be concluded that the contribution of camber can be accounted as small comparing with the effect of toe, since the toe angle causes the largest contribution on the differences between the conventional method and the proposed approach. Nevertheless, it can be seen that a cambered wheel can compensate the effect of toe angle on the overall loss. Even though these numbers are rough estimations and can vary from vehicle to vehicle, it can be comprehended how the fuel efficiency can be affected by the chassis dynamics during a real-world driving scenario.

Included in the driving pattern are the street designs (Ericsson, 2000; Brundell-freij and Ericsson, 2005) which imposes not only straight driving but also many turns and manoeuvres while driving and affecting the lateral dynamics of the vehicle. This imposes extra load transfer and suspension deflection, which also might affect the range of toe and camber variations. Therefore, among all other influential parameters mentioned by other researchers on the existing differences between the certification results and the real world driving, there is also lack of accurate representation of vehicle components' effect and chassis behaviour in driving cycles during the certification process that adds additional discrepancy to the estimation of emissions and environmental impacts of a vehicle.

Though the driving cycles have been subjected to modification and revision since they were introduced to the automotive industry, it seems necessary to consider the influence of vehicle settings on rolling loss to gain a more realistic understanding about the fuel economy and emission characteristics of a vehicle during real driving scenarios. The results of this work will not only help the legislators to further improve the test related procedures and define more clear guidelines for manufactures during measurements. It will also be valuable for car manufacturers as a hint for further considerations during the vehicle design and the homologation process, in order to improve their design and test procedures to reduce the environmental impacts. The result can also be useful to promote the test benches such that the mentioned effects on rolling loss estimations can be captured during type approval. Last but not least, the results of this paper can be an initiative to think about future technologies of chassis and their possible role to decrease the fuel consumption.

\section{Acknowledgment}

The financial support from the Centre for $\mathrm{ECO}^{2}$ Vehicle Design at KTH Royal Institute of Technology is gratefully acknowledged.

\section{References}

Ali, R. et al, 2013. Prediction of rolling resistance and steering characteristics using finite element analysis truck tyre model. Int. J. Veh. Syst. Model. Test. 8 (2), 179-201.

Amirjamshidi, G., Roorda, M.J., 2015. Development of simulated driving cycles for light, medium, and heavy duty trucks: Case of the Toronto Waterfront Area. Transp. Res. Part D 34, 255-266.

Andre, M., 2004. The ARTEMIS European driving cycles for measuring car pollutant emissions. J. Sci. Total Environ. 334-335, 73-84.

André, M., et al., 1995. Driving Cycles for Emission Measurements under European Conditions. SAE International, 950926.

Barlow, T.J. et al, 2009. A Reference Book of Driving Cycles for Use in the Measurement of Road Vehicle Emission. Transport Research Laboratory, Berkshire, United Kingdom.

Bata, R., et al., 1994. Heavy Duty Testing Cycles: Survey and Comparison. In: International Truck \& Bus Meeting \& Exposition, Seattle, WA.

Bode, O., Bode, M., 2013. Untersuchung des Rollwiderstands von Nutzfahrzeugreifen auf echten Fahrbahnen. FAT- Schriftenreihe, 255.

Brundell-freij, K., Ericsson, E., 2005. Influence of street characteristics, driver category and car performance on urban driving patterns. Transp. Res. Part D 10, 213-229.

Davari, M.M., et al., 2015. A multi-line brush based tyre model to study the rolling resistance and energy loss. In: Proceedings of 4th International Tyre Colloquium: Tyre Models For Vehicle Dynamics Analysis, Guildford, UK.

Davari, M.M., 2015. A tyre model for energy studies in vehicle dynamics simulations. Licentiate Thesis in Vehicle Engineering. KTH Royal Institute of Technology, Sweden.

Davari, M.M. et al, 2017. Extended brush tyre model to study rolling loss in vehicle dynamics simulations. Int. J. Veh. Des. 73 (4), 255-280.

Dembski, N., Guezennec, Y., Soliman, A., 2002. Analysis and Experimental Refinement of Real-world driving Cycles. SAE International.

Ericsson, E., 2000. Variability in urban driving patterns. J. Transport. Res. Part D 5, 337-354.

Hadekel, E., 1952. The mechanical characteristics of pneumatic tyres. No Ati 92172, S \& T MEMO NO 10/52, British Ministry of Supply.

Hung, W.T. et al, 2007. Development of a practical driving cycle construction methodology: a case study in Hong Kong. Transp. Res. Part D 12, 115-128. Kamble, S.H., Mathew, T.V., Sharma, G.K., 2009. Development of real-world driving cycle: case study of Pune, India. J. Transport. Res. Part D 14, 132-140. Kiencke, U., Nielsen, L., 2003. Automotive Control Systems: For Engine, Driveline, and Vehicle. Springer Verlag, Germany.

Kishan, S., DeFries, T., Weyn, C., 1993. A study of light-duty vehicle driving behavior: application to real-world emission inventories. In: Fuels and Lubricants Meeting and Exposition. Philadelphia, PA.

Krantz, W., Neubeck, J., Wiedemann, J., 2013. Sensitivitätsanalyse rollwiderstandsrelevanter Einflussgrößen bei Nutzfahrzeugen -. Teile 1 und 2, FATSchriftenreihe, 258 
Kühlwein, J., 2016. The Impact of Official Versus Real-World Road Loads on co2 Emissions and Fuel Consumption of European Passenger Cars. International Council on Clean Transportation Europe, Berlin.

MSC Software, ADAMS. Available at: <http://www.mscsoftware.com> [accessed February 15, 2016].

Peckelsen, U., Gauterin, F., 2013. Einfluss realer Betriebsbedingungen auf den Radwiederstand. Automobil Technische Zeitscrift (ATZ) 115 (11), $916-921$. Pelkmans, L., Debal, P., 2006. Comparison of on-road emissions with emissions measured on chassis dynamometer test cycles. Transp. Res. Part D 11, 233241.

Rapone, M., et al., 1995. Experimental Evaluation of Fuel Consumption and Emissions in Congested Urban Traffic. SAE International.

Sandberg, T., 2001. Heavy Truck Modelling for Fuel Consumption: Simulations and Measurements. Licentiate thesis. Linköping University, Linköping, Sweden.

UNECE, 2016. The United Nations Economic Commission for Europe (UNECE). Available at: <http://www.unece.org/info/ece-homepage.html> [accessed February 15, 2016].

Wang, Q. et al, 2008. Characterization of vehicle driving patterns and development of driving cycles in Chinese cities. J. Transport. Res. Part D 13, $289-297$. Wong, Y.Y., 2001. Theory of Ground Vehicles. John Wiley \& Sons, New York, USA. 